\title{
The Impact of VAT and the Minimum Wage on the Economy of Kosovo
}

\author{
Artan Haziri' ${ }^{1}$, Blerona Shala ${ }^{2 *}$ \\ ${ }^{1}$ Pjeter Budi College, Pristina, Kosovo \\ ${ }^{2}$ Faculty of Economics, University of Pristina "Hasan Pristina", Pristina, Kosovo \\ Email: *bleronashala1@gmail.com
}

How to cite this paper: Haziri, A. and Shala, B. (2021) The Impact of VAT and the Minimum Wage on the Economy of Kosovo. Open Access Library Journal, 8: e7701.

https://doi.org/10.4236/oalib.1107701

Received: June 26, 2021

Accepted: August 20, 2021

Published: August 23, 2021

Copyright ( 2021 by author(s) and Open Access Library Inc.

This work is licensed under the Creative Commons Attribution International License (CC BY 4.0).

http://creativecommons.org/licenses/by/4.0/

\section{(c) (i) Open Access}

\begin{abstract}
To achieve political prosperity and stability, national governments aim to achieve economic equilibrium. The government uses various instruments to stimulate economic growth, reduce unemployment and achieve macroeconomic objectives. In the context of the slow economic growth of recent years and fiscal pressures, Kosovo faces the complex challenge of economic development. Unemployment continues to be at a high rate. This is best shown by the large application for work visas in western countries, especially in Germany and Croatia. The demand for labor is still very low and creating an environment that will favor the creation of sustainable jobs is a challenging task that requires multidimensional reforms in the economy. However, this paper addresses the issue of the impact of fiscal policy on debt forgiveness to businesses, the impact of changing the VAT rate, the eventual increase of the minimum wage and its impact on businesses, the tax imposed on Serbian products and its impact on our products. The purpose of this paper is to show that fiscal policies have a key role in the development of a business as the eventual change of fiscal policies, i.e. profit tax, value added tax, taxes, wages or debt forgiveness directly affects the business activity.
\end{abstract}

\section{Subject Areas}

Accounting, Financial Reporting

\section{Keywords}

Fiscal Policy, Debt Forgiveness, VAT Change, Minimum Wage, Tax on Serbian Products

\section{Introduction}

The level of informality in the economy is still high and, despite initial steps by 
the customs and tax administrations, further coordination efforts between relevant institutions and law enforcement bodies are needed to fight the informal economy and customs fraud [1]. Kosovo has a long history of state domination of economic and financial systems, which has led to a limited degree, volume and experience of the private economy. The transition phase which has been prolonged in Kosovo has greatly affected the economic and social situation of the citizens of Kosovo [1]. Only an appropriate fiscal policy will be able to gradually bring the country to a more satisfactory level of economic growth. During the post-war years, there was an economic growth of a symbolic character, which was mainly attributed to revenues (remittances) from western countries or the United States of America. Kosovo since the formation of the interim government from 2002 which was under the supervision of UNMIK until 2008 when it declared independence has managed to make progress in increasing the budget over the years. Initially, the budget of Kosovo in the post-war years had reached the value of close to 500 million euros and today in 2019 the budget of Kosovo is over 2 billion euros. In addition, profit tax has managed to create a budget increase over the years, which automatically creates economic growth. Political divisions in Kosovo have made it difficult for the country to bring a unified position to negotiations. Kosovo spring 2021 leadership changes could bring greater internal cohesion and coordination but also could bring a more reachable approach to relations [2].

\section{Theoretical Framework}

When the government decides on the goods and services it purchases, the transfer payments it distributes, or the taxes it collects, it is engaging in fiscal policy. The primary economic impact of any change in the government budget is felt by particular groups-a tax cut for families with children, for example, raises their disposable income [3].

Fiscal policy consists of using taxes and government spending as tools to influence a country's macroeconomic indicators [4]. Government expenditures affect the general level of expenditures of the economy, i.e. the level of GDP and consequently the level of employment, inflation, etc. Fiscal policy directly or indirectly affects the country's economy. As the economy shifts from a recession and into an expansion, broader economic conditions will generally improve, whereby unemployment falls and wages and private spending increases [5].

Another impact on the increase of the budget has had the payment of various taxes such as: Municipal taxes, administrative taxes, road taxes, ecological taxes, court taxes, etc.

\subsection{Hypotheses}

1) The change of VAT rates from fixed VAT $16 \%$ to variables $18 \%$ and $8 \%$ has reduced the price for basic products.

2) The eventual increase of the minimum wage would have a positive impact on businesses. 
3) The $100 \%$ tax imposed on Serbian products has increased the demand for local products.

\subsection{Fiscal Policy}

Decisions made in fiscal policy are not easy because changing one variable can cause other variables to change and take the wrong direction, so fiscal policy is considered a complex area which needs to be analyzed in detail. The fiscal system in Kosovo faces a variety of ideas and challenges. Without intending to highlight any specific problems within this system, some of the shortcomings are quite obvious and do not require significant commitment to solve. Others call for radical reforms on a general scale [5]. The reduction of tax rates made by the Government has been the most appropriate step in post-war Kosovo. Such a decision has helped develop businesses and distribute the tax burden to all participants. The highest positivity comes from the reduction of corporate tax from $20 \%$ to $10 \%$. This made Kosovo much more attractive in the global market. However, in the wave of optimism, the increase of VAT from 15\% to $16 \%$ remains forgotten. Although it was proclaimed as an increase of "only $1 \%$ " the truth is that VAT has increased by 1 percentage point and this is equal to $6.6 \%$.

\subsection{The Impact of Fiscal Policy on the Business Environment in Kosovo}

Fiscal policy is the means by which a government adjusts its spending levels and tax rates to monitor and influence a nation's economy. It is the sister strategy to monetary policy through which a central bank influences a nation's money supply. Fiscal policy is the use of government spending and taxation to influence the economy. Governments typically use fiscal policy to promote strong and sustainable growth and reduce poverty [6]. Initially the corporate income tax from the establishment of TAK (Kosovo Tax Administration) was 20\% until the end of 2009 and with the beginning of 2010 this fee has changed and has been reduced to $10 \%[7]$.

This has had a positive impact on businesses operating as corporations in Kosovo (Limited Liability Companies, Joint Stock Companies, etc.) to turn this difference of $10 \%$ into profit or investment for the company. This policy has also had a positive impact on the state budget, as on the one hand corporate tax revenues have been reduced, but on the other hand tax evasion has been reduced and a balance has been created in the Kosovo budget. Taxpayer compliance can be expected to come under pressure if the economy continues to grow slower than in past years. Maintaining compliance in the face of slower growth is one of the key challenges facing the SAT in the period ahead [8].

The tax for businesses dealing with commercial activities is $3 \%$ and has not changed, but for service activities the tax was 5\% until 2013 and then it was changed and increased to $9 \%$ [7]. This has negatively affected many businesses which have been forced to change the form of taxation and switch to real income tax. Businesses have estimated that this is a better solution when it is known that 
real income tax costs are accepted and biased taxes are not [7].

Another impact was the rent tax regulation where the rate of $9 \%$ has not changed but the form of payment has changed. Now, with the new law from 2015, all businesses are obliged to pay rent tax for the building they own and to deduct this value from the owner of the building, i.e. to pay the gross rent (minus rent $\operatorname{tax})=$ Net rent. The same has happened with businesses that have meat and dairy products which they have bought from farmers have been forced to pay $3 \%$ of the value they have bought from them and withhold this value at source [7].

In both cases this has been favorable for the state as it has managed to better control the rental facilities and farmers but has created a "conflict" between the aforementioned parties over who should pay that part of the tax.

Another impact of fiscal policy is value added tax (VAT). This tax is otherwise known as the type of tax paid by the consumer. However, in Kosovo, the state first obliges businesses to pay VAT at customs when importing goods and then take that value as deductible (credit) and the moment the goods are sold, the final consumer pays the full value of VAT. This is a burden for businesses as they have to share a large part of their money for VAT payment at customs.

VAT initially until 2008 was $15 \%$ for all products but from the beginning of 2009 the VAT rate has increased to 16\% [7]. This policy has forced businesses to increase their prices but not profit, as in this case the revenues of the state and not the business have increased. However, in September 2015, the state set for the first time a variable VAT rate where it decided to charge basic products with $8 \%$ VAT and luxury products with $18 \%$ VAT. This results in the possibility for businesses to reduce prices for basic products and the demand for these products to be even greater [7].

The opposite has happened with luxury products where with the increase of VAT all the prices of products have automatically increased which has resulted in the decrease of the demand for products.

There was also another change in 2015 where the threshold for VAT registration was reduced from 50,000 to 30,000 euros and this has negatively affected the enterprises of small and medium as businesses are required to receive VAT invoices to create a credit balance in purchases and to have that reserve at the time the goods are sold. High interest rates in banks have also been affected, where initially there were rates of up to $20 \%$ in loans to businesses, it is known that many businesses operate with a margin of less than $20 \%$ and this has automatically sent businesses into bankruptcy. Another impact has been the law on debt forgiveness, which has greatly affected businesses, especially those with high turnover. Various researches show that many businesses have benefited from the forgiveness of their debts to public enterprises and the Tax Administration of Kosovo [7].

Fiscal cash registers have also been a burden for businesses as a monopoly of theirs was initially created and the cash registers were initially sold at a fairly 
high price that does not correspond to their real price and this has been a great burden they have paid businesses. When we add to this the annual maintenance of the cash register as insurance in case of failure then this is quite harmful especially for small and medium businesses that have lower turnover and profit. However, the price of cash registers has started to fall at the moment when the vast majority of businesses have been equipped and the demand for them has fallen.

From 1 September 2015, the Government of Kosovo, respectively the Ministry of Finance has decided to change the VAT law by creating for the first time a variable or variable VAT. Initially the VAT until 2008 was 15\% then from 2009 to September 2015 the VAT was 16\%. With the change of the VAT law, VAT has been transformed from fixed VAT to variable VAT, where 2 VAT rates of $18 \%$ and $8 \%$ have been applied [7].

The application of the rate of $8 \%$ is applied to basic products such as (Drugs, Flour, Oil, Milk, etc.) while other products which are considered as luxury products are listed at the rate of $18 \%$ [7].

\section{Methology}

The instrument used in this research is the questionnaire-survey as the easiest tool to access with the respondents. Anonymity was promised and kept and the willingness to attend was very high. The number of participants in this survey counts 30 participants. The questionnaire contains 7 closed questions where the evaluation is done based on the Liqueur scale with 1 - 4 options to choose from. Data collection was completed during March 2021. The questions were understandable and the distribution was done mainly through E-mail and media networks.

As we can see from the data of the respondents we have an approximation of those who think that this change has had a positive impact and those who think that it has had a negative impact.

Respondents who were asked about the question how this change in the VAT rate has affected gave their answers where $42.40 \%$ think that this change has negatively affected businesses, $39.40 \%$ think that this has had a positive impact on businesses while $18.20 \%$ think it has had no impact (Figure 1).

As we are aware, value added tax is a tax paid by the consumer and for this we addressed the respondents how they think that this change has affected in practice where we have a reduction of VAT on basic products from $16 \%$ to $8 \%$, i.e. a $100 \%$ discount on the VAT rate.

$39.40 \%$ of the respondents think that this has not affected the reduction of prices for basic products, $30.30 \%$ think that prices for basic products have decreased with the change of the VAT rate and $30.30 \%$ think that it has not affected prices at all (Figure 2).

From the research we can understand that businesses have not respected the changes in VAT, enabling themselves to bring an even greater profit as the value 
How has the change in the VAT rate from $16 \%$ to $18 \%$ and $8 \%$ affected?



Figure 1 . The change of the value added tax from fixed VAT $16 \%$ to vaeable $18 \%$ and $8 \%$, which has reduced the price for basic products.

\section{Has the reducted value of VAT for basic products to $8 \%$ reduced prices?}

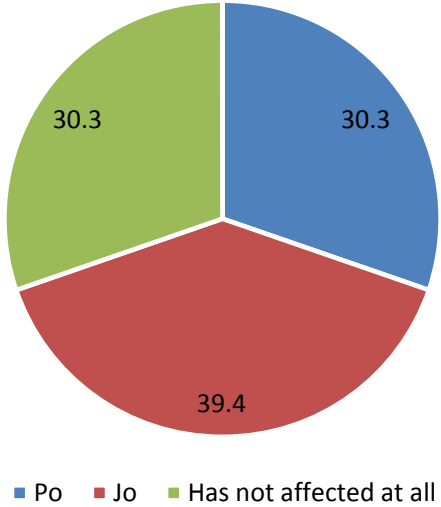

Figure 2. The reduced value of VAT for basic products to $8 \%$ reduced prices.

of $8 \%$ which should have been reduced is automatically returned to profit for the business as it is obliged to pay $8 \%$ VAT to the state while the other $8 \%$ has been turned into profit.

In this regard, the mechanisms responsible for price regulation should take appropriate measures to regulate this issue as this has an impact on consumers, especially when it is known that we are dealing with basic products such as oil, flour, sugar, medicines, etc.

The opposite of what has happened with the elementary products is in the luxury products where we have with the new VAT rate we have an increase of $2 \%$. It is known that VAT is a tax paid by the consumer and this directly affects his pocket.

$87.90 \%$ of respondents regarding this issue think that prices have increased with the increase of the VAT rate, $9.10 \%$ think that prices have not increased and $3 \%$ think that this has not affected prices at all (Figure 3). 


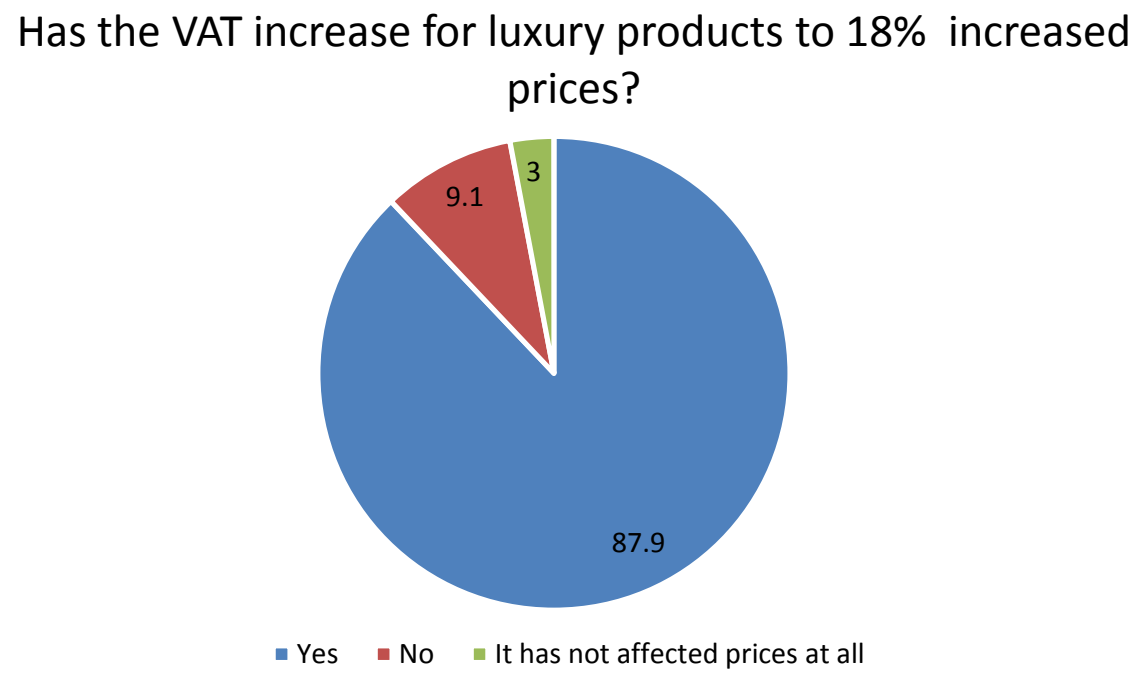

Figure 3. The VAT increase for luxury products to $18 \%$ that has increased prices.

The increase of prices in this case is normal to happen because the eventual changes of VAT are a burden on the consumer, but the same as the increase of prices of luxury products, the same should have happened to the elementary products where it should have discounted prices.

Based on the analysis, all this change of VAT has gone to the benefit of businesses as they have benefited in the case of basic products when it is known that they are the products with the largest market share and are known to be products that every family consumes courses in luxury products we have a smaller share of consumers even though we have many more items who are participants at the rate of $18 \%$.

Value added tax is one of the taxes that brings the most revenue to the Kosovo budget with about $47 \%$ share in the Kosovo budget. Initially the value added tax is paid at the moment of arrival of the goods at Kosovo Customs if the goods are imported but if the goods are domestic production then VAT is paid to the Tax Administration of Kosovo and at the moment of product entry all VAT is paid by the consumer last.

One of the other changes that have occurred at the same time with the change of the VAT rate is the change of the VAT threshold from 50,000 euros as it was until September, 2015 to 30,000 euros and this has definitely benefited the state. as the turnover of most small and medium-sized businesses ranges between 30,000 and 50,000 euros.

The other change was that the way to reach the VAT threshold will be done within the calendar year 01 January to 31 December, a method that has changed the old form when calculating the VAT threshold within the last 12 months.

$75.80 \%$ of respondents think that the change of VAT has had a positive impact on the increase of the state budget, $21.20 \%$ think that it has not had any impact while $3 \%$ think that it has had a negative impact as the budget has been reduced (Figure 4). 


\section{How do you think this change in VAT has affected the state budget?}

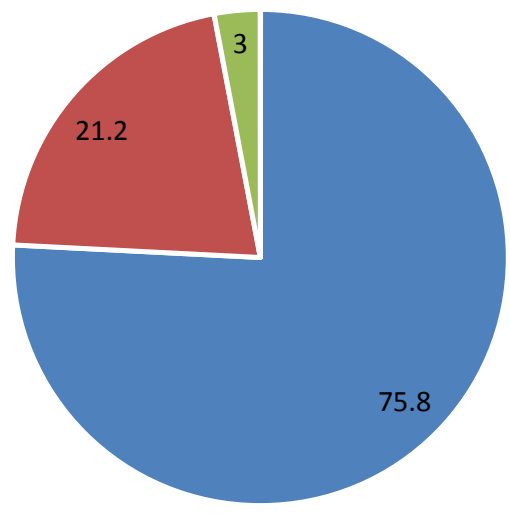

- Positively as the budget has increased

- Negatively as the budget has been reduced

- Has not affected at all

Figure 4. The change in VAT that has affected the state budget.

Most of the respondents were businesses and most of them $72.70 \%$ think that the government had better opportunities, $18.20 \%$ think that the government should not have changed the VAT law and $9.10 \%$ think that this government decision has been the best solution (Figure 5).

VAT changes have not been well received by most businesses as the increase in the VAT rate has increased prices and this has affected the consumer basket.

The other impact has been the lowering of the threshold from 50,000 euros to 30,000 and this has affected most businesses as at the moment of reaching the threshold for VAT businesses are obliged to provide VAT invoices to reduce VAT that they realize on sale otherwise it will to be charged with all VAT on sale which is a big burden for businesses especially small ones.

On the other hand, the government has used a very good strategy to bring revenues to the Kosovo budget where it is known that a large part of the products participate in luxury products where there has been an increase from $16 \%$ to $18 \%$ while the best strategy of the government has been lowering the VAT threshold from 50,000 euros to 30,000 euros where it is known that a large number of small and medium businesses have reached the VAT threshold bringing quite large revenues to the budget.

It is known that the Kosovo budget realizes the largest revenues from value added tax, profit tax through responsible institutions such as Kosovo Customs and Kosovo Tax Administration through imports to sales to the final consumer.

When asked by 33 respondents how they think the increase of the minimum wage in Kosovo would affect, we received the following answers:

$68 \%$ think that the increase of the minimum wage would have a positive impact on businesses, $31 \%$ think that it would have a negative impact and $1 \%$ think that there will be no impact (Figure 6). 


\section{Do you think that the government should have used any strategy regarding the change of the VAT rate?}

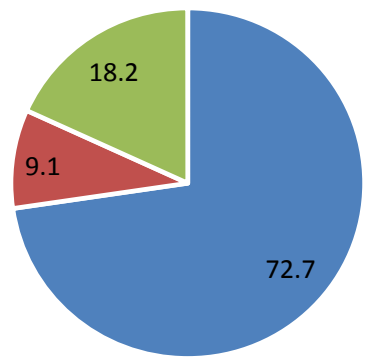

\footnotetext{
- Yes, the Government has had better opportunities

- No, this government has been the best choice

- The government did not have to change the VAT law
}

Figure 5. The government usage of strategy regarding the change of the VAT rate.

\section{How would the increase in the minimum wage affect Kosovo businesses?}

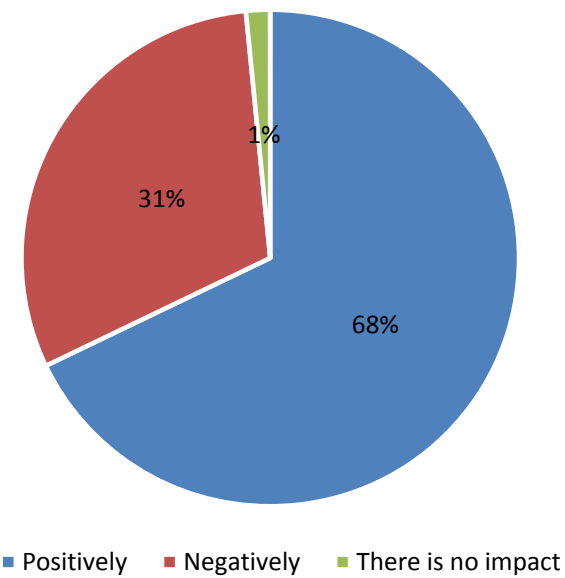

Figure 6. The increase in the minimum wage affect Kosovo businesses.

Most respondents think that raising the minimum wage would have a positive impact even though businesses will be burdened with higher costs of wages, contributions and taxes. In the survey we conducted with 33 respondents we received the following answers to the question of how the tax on Serbian products had an impact on the stimulation of local products: $84.80 \%$ think it had a positive impact, $12.10 \%$ think it had a negative impact and $3.10 \%$ think it has not affected at all.

In the survey we conducted with 33 respondents we received the following answers to the question of how the tax on Serbian products had an impact on the stimulation of local products: $84.80 \%$ think it had a positive impact, $12.10 \%$ think it had a negative impact and 3.10\% think it has not affected at all (Figure 7). The tax, despite the positive effects, also had its weaknesses. The tax was imposed for a very short period of time and a proper analysis of the manner of 


\section{How do you think the $100 \%$ tax on Serbian products has affected the stimulus to local products}
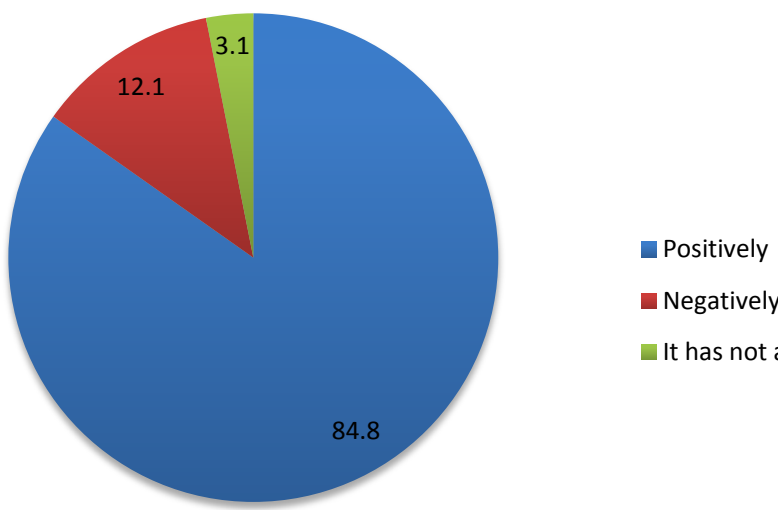

Figure 7. The $100 \%$ tax on Serbian products, that has affected the stimulus to local products.

implementation was not done. The Ministry of Trade and Industry, in the department where trademarks are registered, lacked a proper database of international trademarks. The notes were half-hearted and left much to be desired. The criteria for what the international brand meant were not set.

\subsection{Verification of Hypotheses}

Based on the questionnaire, it turns out that the first hypothesis has been rejected and the VAT changes have not reduced the prices of basic products.

The second hypothesis is accepted, because the increase in pay has a positive effect on businesses, but most of these businesses do not have in their plans to increase the number of employees.

\subsection{The Third Hypothesis Is Accepted as Correct, but with High Doubts}

However, the tax, despite the positive effects, also had its weaknesses. The tax was imposed for a very short period of time and a proper analysis of the manner of implementation was not done. The Ministry of Trade and Industry, in the department where trademarks are registered, lacked a proper database of international trademarks. The notes were half-hearted and left much to be desired. The criteria for what the international brand meant were not set.

At first the tax rate was small, 10\%, and did not attack international brands. The effect was negligible and this was done at $100 \%$ for products imported from Serbia and Bosnia and Herzegovina. Point 2 of the decision of the Government of Kosovo No. 01/76 dated 21.11.2018 has the following content.

Notwithstanding the origin of the goods provided for in paragraph 1 of this Decision, the measure of $100 \%$ shall not apply to well-known trademarks of other countries which are produced in Serbia and Bosnia and Herzegovina, which are part of the annex attached to this Decision.

Only 8 businesses were entered in this register, leaving it to be suspected that: 
either it was made in agreement by government officials or you were their respondent. The second hypothesis was later argued that business discrimination was not the cause of the selection, as many, many protected international trademarks were registered in the database but were not allowed to import.

The government does not respect the decision it had taken itself and committed a violation, because after 21.11.2018, with decision No. 01/76, it had included in the annex only 8 businesses with the right to import, nine international trademarks that were allowed to import.

Some businesses had large quantities of goods in their customs warehouses which were then allowed by another decision to clear those goods without $100 \%$ tax in February 2019.

The government did not have a plan to inform importers in Kosovo to find alternative markets for their supplies.

\section{Conclusion}

Looking at it from the economic point of view, we have some of the positive effects which are: Increasing the consumption of domestic products, increasing tax revenues, creating preconditions for the replacement of Serbia-fighting Serbia's dumping policies in the Kosovo market, promoting "Made in Kosovo" products, avoiding the perception that Kosovo is dependent on Serbian products, while as negative effects are seen: Increase of prices for certain products in the Kosovo market, damage to the part of local producers who have imported raw materials from Serbia, increase of smuggling especially in the north of the country, import of Serbian goods from other countries in the region and increased imports.

\section{Conflicts of Interest}

The authors declare no conflicts of interest.

\section{References}

[1] European Commission (2020) Communication from the Commission to the European Parliament, the Council, the European Economic and Social Committee and the Committee of the Regions. 35 p.

https://eur-lex.europa.eu/legal-content/EN/TXT/PDF/?uri=CELEX:52020DC0324\& from $=\mathrm{EN}$

[2] Congressional Research Service (2021) European Communication from the Commission to the European Parliament and the Council. Science Direct, 2, 9-10.

[3] Weil, D. (2014) Health and Economic Growth. In: Aghion, P. and Durlauf, S., Eds., Handbook of Economic Growth, Vol. 2, Elsevier, North-Holland, 623-682. https://econpapers.repec.org/bookchap/eeegrochp/2-623.htm https://doi.org/10.1016/B978-0-444-53540-5.00003-3

[4] Jahan, S., Mahmud, A.S. and Papageorgiou, C. (2014) What Is Keynesian Economics? Finance \& Development, 51, 72-84. https://www.elibrary.imf.org/view/journals/022/0051/003/article-A015-en.xml

[5] Congressional Research Service (2021) Fiscal Policy: Economic Effects. https://fas.org/sgp/crs/misc/R45723.pdf 
[6] Horton, M. and El-Ganainy, A. (2020) Fiscal Policy: Taking and Giving Away. International Monetary Fund, 12, 19-29.

[7] Tax Administration Kosovo (2021) Tax legislation of Kosovo. https://www.atk-ks.org/wp-content/uploads/2017/08/VAT_CHANGE_RATE-FRO M_15TO16.pdf

[8] John, B. and Zhang, Z.Y. (2017) Chapter 3. Strengthening Tax Administration. In: Raphael Lam, W., Rodlauer, M. and Schipke, A., Eds., Modernizing China, International Monetary Fund, USA.

https://www.elibrary.imf.org/view/books/071/23209-9781513539942-en/ch03.xml 